\title{
A rare case of acute scrotum presenting as intraoperative surprise
}

\author{
Balachandra Menon, Atul Sahai, Vipin Venugopal Nair, Rajiv Singh \\ Armed Forces Medical College, Pune, India
}

\begin{abstract}
Keywords: Acute scrotum; leiomyoadenomatoid tumour; epididymis; paratesticular tumours; benign urological tumours
\end{abstract}

\section{Introduction}

Leiomyomas are benign tumours that can arise from the smooth muscle component of any tissue. Adenomatoid( tumours arise from the mesothelial elements. But the origin of the leiomyoadenomatoid tumour is not yet clear. We present a case of acute left testicular pain presenting to the surgical emergency department with a surprising outcome. Torsion testis was considered the first provisional diagnosis, but the irregular shape and contour of the testis aroused the suspicion of a tumour [1].

\section{Case presentation}

A 29-year-old male patient presented to a forward military surgical centre located in a conflict zone with acute onset left testicular pain for $3 \mathrm{hrs}$. The onset and progression of pain were rapid and severe. Since the patient was not comfortable with clinical examination, the only inspection could be conducted. The left hemiscrotum was swollen with an irregular contour. The right-sided testis and hernial sites were normal.

Imaging and transferring to a higher centre was impossible due to ongoing conflict in the region. The patient was taken up for emergency exploration. A high inguinal approach was adopted for suspicion of testicular tumours. But testis could not be delivered out through a high inguinal incision due to adhesion to scrotal skin. Hence, a scrotal incision was given for mobilisation. Intra-op there was a palpable hard tumour in the head of the left epididymis and the testis was irregular in shape and firm to hard inconsistency. Testis along with the spermatic cord was completely removed till the deep ring [ Fig 1]. All margins were meticulously excised and specimens were sent for histopathological examination. The external surface of the specimen appeared distorted, but there was no ulceration. Cut surface revealed the presence of a well-

Correspondence: Vipin Venugopal Nair

E-mail: vipinvenugopalnair@gmail.com

(iD) https://orcid.org/0000-0002-8255-516X

Received: 11-06-2021 Accepted: 04-08-2021

DOI: http://doi.org/10.4038/sljs.v39i3.8712 defined, firm, white nodule in the head of the epididymis with no grossly apparent extension into the testicular parenchyma. The testicular parenchyma appeared congested. Sections of the nodule showed a well-circumscribed tumour composed of cystic tubules lined by flattened to cuboidal epithelium with intervening fibrous stroma. The presence of prominent smooth muscle was noted in the stroma. No nuclear atypia, mitosis or necrosis was seen. Sections of the testis showed parenchymal haemorrhages with neutrophilic microabscesses suggestive of acute changes. All the margins were free of tumours. Immuno-histochemistry showed lining epithelial cells of epididymal tumour to be positive for Creatinine-Kinase (CK), Epithelial-Membrane-Antigen (EMA) and negative for CD-34. Smooth muscle component was positive for Smooth-Muscle-Antigen (SMA). Post-op recovery was normal. Abdominal radiology and tumour marker assay for Non-seminomatous Germ Cell tumours were normal.

\section{Discussion}

Primary solid epididymal tumours are rare. They constitute only $5 \%$ of intra-scrotal tumours; $75 \%$ of which are benign. Of the epididymal tumours, $73 \%$ are adenomatoid tumours; $11 \%$ are leiomyomas and $9 \%$ are papillary cystadenomas. Differential diagnoses of epididymal swelling include epididymitis, sperm granuloma, sarcoidosis, tuberculosis or neoplasia. As a rule, solid intra-testicular lesions have a high likelihood of malignancy; extra-testicular lesions are usually benign[2,3].

Adenomatoid tumours are benign and originate from the mesothelial cell. They constitute $30 \%$ of paratesticular tumours and frequently occur in epididymis \& fallopian tubes. Major microscopic features are a glandular pattern with fibrous stroma and cytoplasmic vacuole. Local invasive behaviour is seen rarely. Leiomyoadenomatoid tumour is an extremely rare variety, the histogenesis of which is largely unknown. Some authorities consider this as a subtype of adenomatoid tumour.

The theory of collision neoplasia is the second postulate. Another opinion is that it is an adneomatoid tumour with reactive smooth muscle hyperplasia. Microscopically there are two components; first, the gland-like spaces lined with 


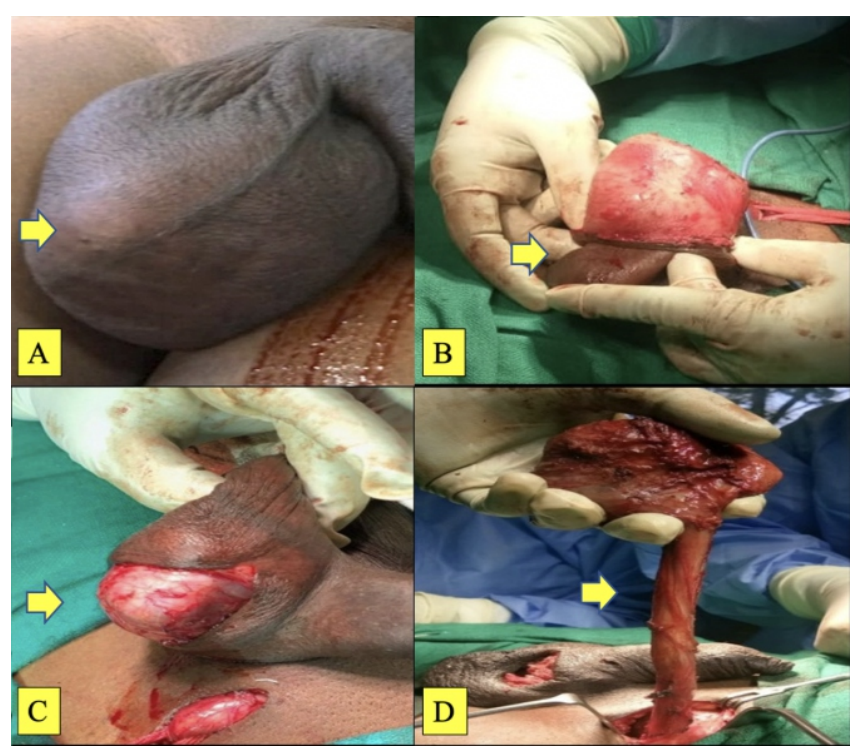

Figure 1.

A. Irregular contour of left hemiscrotum

B. Testis firmly adherent to the scrotal skin

C. Separate scrotal incision

D. Left testis and cord mobilized till deep ring

flattened or cuboidal cells as seen in this case, and secondly, the smooth muscle component with palisades of smooth muscle cells $[4,5,6]$.

Radical orchidectomy was done in this case for suspicion of an underlying tumour of the testis. Otherwise in a diagnosed case of an epididymal tumour, if the frozen section suggests benignity, simple excision of the lesion would suffice.

\section{Conclusion}

Adenomatoid leiomyoma is an extremely rare variety of intrascrotal tumours with very few reported cases in the literature. In a case of an acute scrotum with enlarged and distorted testis, a medical surprise in the form of a tumour must be kept in the back of our mind.
All authors disclose no conflict of interest. The study was conducted in accordance with the ethical standards of the relevant institutional or national ethics committee and the Helsinki Declaration of 1975, as revised in 2000.

\section{References}

1. Kausch I, Galle J, Buttner H, Bohle A, Jocham D. Leiomyoadenomatoid tumour of the epididymis. J Urol. 2002;168(2):636. https://doi.org/10.1016/S0022-5347(05)64697-6

2. Bromby, A. and Cresswell, J. (2014), Differential diagnosis of a scrotal mass. Trends in Urology \& Men's Health, 5: 15-18. https://doi.org/10.1002/tre.373

3. Shipstone, D.. (2006). Pain and swelling of the scrotum, epididymitis and torsion. Surgery. 24. 160-162. https://doi.org/10.1383/surg.2006.24.5.160

4.Delahunt B, Eble JN, Nacey JN, Thornton A. Immunohistochemical evidence for mesothelial origin of paratesticular adenomatoid tumour. Histopathology. 2001;38(5):479. https://doi.org/10.1046/j.1365-2559.2001.1163a.x

5. Cazorla A, Algros MP, Bedgedjian I, Chabannes E, Camparo P, Valmary-Degano S. Epididymal Leiomyoadenomatoid Tumor:

A Case Report and Review of Literature. Curr Urol. 2014;7(4):195-198. https://doi.org/10.1159/000365675

6. Bahuguna G, Misra D, Malhotra V, Sinha A. Multicentric leiomyoadenomatoid tumor of the uterus: a rare and distinct morphological entity. J Obstet Gynaecol India. 2014;64(Suppl 1):152-153.

https://doi.org/10.1007/s13224-014-0527-2

\section{Learning Points:}

- Benign scrotal tumours can present with acute severe symptoms.

- An underlying tumour must always be kept in mind when dealing with acute scrotal cases.

- Leiomyoadenomatoid tumour is a rare benign tumour in the genitourinary tract, more so in the epididymis. 